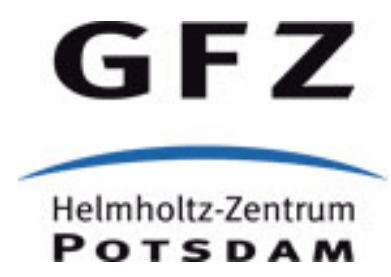

Originally published as:

Mikolaj, M., Meurers, B., Güntner, A. (2016): Modelling of global mass effects in hydrology, atmosphere and oceans on surface gravity. - Computers and Geosciences, 93, pp. 12-20.

DOI: http:/ / doi.org/ 10.1016/ j. cageo.2016.04.014 


\title{
Modelling of global mass effects in hydrology, atmosphere and oceans on surface gravity
}

\author{
M. Mikolaj ${ }^{\mathrm{a}, *}$, B. Meurers ${ }^{\mathrm{b}}$, A. Güntner ${ }^{\mathrm{a}}$ \\ ${ }^{a}$ GFZ German Research Centre for Geosciences, Section Hydrology, Potsdam, Germany \\ ${ }^{b}$ Department of Meteorology and Geophysics, University of Vienna, Vienna, Austria
}

\section{Abstract}

We present a Matlab/Octave-based software tool mGlobe to compute the effect 2 of atmospheric, continental water storage, and non-tidal ocean mass variations on surface gravity. These effects must be considered or reduced prior to any analy4 sis of geophysical phenomena using observations of superconducting gravimeters. Contrary to the alternative providers, mGlobe allows the computation for an ar6 bitrary location worldwide, supports a larger number of input models and offers 7 more flexibility in terms of computation settings. The high number of supported 8 models is important for assessment of model uncertainties. Discrepancies exceeding $75 \%$ were found. The continental water storage effect showed low sensitivity

to spatial and temporal resolution. The deficient temporal resolution affects the non-tidal loading and atmospheric effects significantly. The same holds true for the influence of the spatial resolution on atmospheric effects. To compensate this

*Corresponding author: Tel +49 331 288-28845, Fax: +49 331 288-1570.

Email addresses: mikolaj@gfz-potsdam.de (M. Mikolaj), bruno.meurers@univie.ac.at (B. Meurers), guentner@gfz-potsdam.de (A. Güntner) 
effect, we introduce a site-specific correction factor based on differences between the real topography and model's orography.

Keywords:

Gravity effect, Continental water storage, Non-tidal ocean loading, Atmosphere

\section{Introduction}

Observations of absolute and superconducting gravimeters contain information on the gravity effect of a wide range of phenomena like Earth and Oocean tides, Earth rotation, transport of hydrological and atmospheric masses or the Earth's internal geodynamic processes. Geophysical studies of a specific phenomenon therefore need to comprise the consideration of all sources of gravity variations, provided the magnitude of these variations is in the order of magnitude of the gravity signal of interest. The need for reducing disturbing gravity effects even grows with the ongoing accuracy increase of absolute and superconducting gravimeters. The gravity effect of global-scale water mass transport is a prominent example of a reduction that has emerged in past decades (van Dam and Wahr, 1998; van Dam, 2001) and needs to be considered in order to resolve small gravity changes of up to few tens of $\mathrm{nm} \mathrm{s}^{-2}$. More recent studies (e.g. Boy and Hinderer, 2006; Wziontek et al., 2009) discussed the computation of the continental water storage effect considering different global hydrological models at various sites, concluding that the corresponding gravity effect contributes significantly to the seasonal variation of surface gravity. Depending on the location, the global hydrological effect may exceed or at least interfere with the contribution of the local hydrology (Longuevergne et al., 2009), i.e., water storage variations within few kilometres from the actual point of observation. Numerous studies discussed 
the complex assessment of the local hydrology contribution to gravity variations (e.g. Creutzfeldt et al., 2010; Hasan et al., 2006; Hinderer et al., 2012; Virtanen et al., 2006). The continental water storage effect plays a key role in such studies because using a different global hydrological model or the neglecting the global effect may affect the conclusions in terms of the magnitude and phase of local water storage variations. Similarly, this applies for the purposes of validation or calibration of local hydrological models using gravity residuals (e.g. Creutzfeldt et al., 2012; Naujoks et al., 2010).

To meet the increasing demand for assessing the continental water storage gravity effect, the GGP/Strasbourg Loading Service ${ }^{1}$ (Boy et al., 2009) provides the corresponding time series for a selected group of superconducting gravimeters using four global hydrological models. In addition, estimations of the non-tidal ocean loading and atmospheric effect are provided. The non-tidal ocean loading is the effect of the ocean mass transport uncorrelated to the tidal processes. The tide related mass transport is reduced within the tidal analysis of observed gravity variations or by means of ocean tide models ${ }^{2}$ (e.g. Egbert and Erofeeva, 2002; Lyard et al., 2006; Matsumoto et al., 2000). Similarly to the continental water storage effect, previous studies (e.g. Boy and Lyard, 2008; Kroner et al., 2009) showed that the non-tidal ocean loading effect must be considered also at sites hundreds of kilometres away from the coast and that the discrepancies between different ocean models can exceed the amplitude of respective variations.

Besides Earth tides, the atmospheric effects are the most important source of gravity variations. Generally, two different approaches are used for the computa-

\footnotetext{
${ }^{1}$ http://loading.u-strasbg.fr/GGP

${ }^{2}$ http://holt.oso.chalmers.se/loading/
} 
tion of the atmospheric effect. The empirical approach seeks the relation between the observed air pressure variation and gravity (e.g. Warburton and Goodkind, 1977). Typically, the least square adjustment between the gravity residuals and the air pressure yields an admittance factor of about $-3 \mathrm{~nm} \mathrm{~s}^{-2} / \mathrm{hPa}$. The physical approach utilizes atmospheric models for the determination of the mass distribution that is then transformed to gravitational and loading effects (e.g. Merriam, 1992). The latter approach allows to take into account the gravity effects of remote atmospheric masses, i.e., variations that are not correlated to the local air pressure. Besides the GGP/Strasbourg Loading Service, global atmospheric corrections are also provided by the Atmacs service ${ }^{3}$ (Klügel and Wziontek, 2009). Compared to the GGP Loading Service, Atmacs utilizes weather models with higher temporal (3 versus 6 hours) and spatial resolution ( $7 \mathrm{~km}$ versus $\left.0.75^{\circ}\right)$, but with worse time coverage (starting 2004 versus 1979). The common denominator for both services is the restricted number of available sites and the fact that the provided atmospheric effect does not take the real topography into consideration.

\section{2. mGlobe overview}

To enable the computation for an arbitrary location worldwide, we have developed a comprehensive Matlab ${ }^{\circledR} /$ Octave-based toolbox (mGlobe) for the computation of the effect of the continental water storage, non-tidal ocean loading and atmosphere on surface gravity. To tackle the significant discrepancies between different models as introduced above, mGlobe enables the loading of a majority of freely available models by default (see Table 1), and contains a build-in conver-

\footnotetext{
${ }^{3}$ http://atmacs.bkg.bund.de
} 
sion tool for other hydrological or ocean models. This option allows for including models like the WaterGAP Global Hydrology Model (WGHM) (Döll et al., 2003) or similar models that represent total continental water storage variations in different storage compartments. Considering total water storage variations is of particular relevance for comparing global hydrological models to GRACE (e.g. Van Camp et al., 2014; Neumeyer et al., 2008; Weise et al., 2012). The computation of the atmospheric effect utilizes the ERA Interim or MERRA pressure level data and surface level data downloaded in NetCDF file format. A digital elevation model (DEM) can be utilized in the computation of hydrological as well as atmospheric effects. A DEM is particularly important for computation of the atmospheric effect, as the impact of a low spatial resolution of atmospheric models will be minimized by using the DEM instead of gravity observations themselves. Thus, essential gravity variations that are anti-correlated to air pressure but of different origin will not be reduced by mistake. Additional features like the restriction of the computation to a certain basin, dividing the gravity contributions into the loading and the attraction part or the integration of user-provided high-resolution coastlines allow to obtain more specific results. In these respects, mGlobe provides more flexibility than the existing services. In mGloble, both the global and the local zone are included in the computation of atmospheric effects whereas the local zone is excluded from the computation of hydrological effects. The latter is due to the high spatial and temporal variability of hydrological processes which is not reflected in global hydrological models. A detailed local hydrological model including high-resolution information on topography and infrastructure (e.g., to capture the shielding effect of the gravimeter building) and in-situ hydrological monitoring data are recommended for subtracting the local hydrological effect 
(Creutzfeldt et al., 2008). In mGloble, the radius of the local zone around the site of interest can be set between $0.05^{\circ}$ and $1.0^{\circ}$ (spherical distance). For all effects, the user can set the position, computation period and the time resolution. The more specific settings are described in detail in the corresponding sections below.

The mGlobe graphical user interface of the continental water storage console is shown in Figure 1. The Matlab version requires Mapping and Statistics toolboxes and can be downloaded from github.com/emenems/mGlobe. The Octave version can be downloaded from github. com/emenems/mGlobe_octave.

\section{Study sites}

In this study, mGlobe results were evaluated at three sites equipped with a superconducting gravimeter (SG), namely Vienna, Conrad observatory (both in Austria) and Sutherland (South Africa, Table 2). The SG in Vienna was installed in an underground laboratory from August 1995 until the end of October 2007. Afterwards, this gravimeter has been moved to the Conrad observatory in the north-eastern margin of the Eastern Alps. The upgraded dual sphere SG in Sutherland has been in operation since the end of 2009. The SG observations in Vienna and at the Conrad observatory were acquired from their operators while the observations of the SG in Sutherland were downloaded from the ISDC (Information System and Data Center for geoscientific data) data servers ${ }^{4}$. Prior to the mGlobe evaluation, the gravity time series were corrected for steps and spikes using the TSoft software (Van Camp and Vauterin, 2005), decimated to one hour sampling and corrected for tides, polar motion, length of day and instrumental trend. The

\footnotetext{
${ }^{4}$ http://isdc.gfz-potsdam.de
} 
tidal parameters were derived from tidal analyses using the ETERNA package (Wenzel, 1996), i.e., the tidal parameters include the ocean tidesłoading effect. The instrumental trend was estimated using the least square adjustment. Absolute gravity observations could not be used at Vienna due to accuracy limitations caused by high site noise. No absolute gravity observations were available for the Sutherland site.

\section{Continental water storage}

The aim of the continental water storage module in mGlobe is to compute the non-local hydrological contribution to surface gravity variations. This contribution can be divided into a loading and gravitational part. The loading part is related to the surface deformation caused by mass transport, i.e., water storage changes. The gravitational part is related to the vertical component of the Newton's attraction of water masses. The calculation itself is divided into several zones depending on the spherical distance $(\psi)$ between the mass and the measurement point. The closer to the measurement point, the higher is the degree of spatial discretization, i.e., the original model values are linearly interpolated into a finer grid. The loading effect per unit mass $\left(g^{L}\right)$ is in all zones computed using Green's function formalism as given by Farrell (1972)

$$
g^{L}(\psi)=-\frac{g}{M} \sum_{n=0}^{\infty}\left(2 h_{n}-(n+1) k_{n}\right) P_{n}(\cos \psi),
$$

where the $h_{n}$ and $k_{n}$ symbols represent the load Love numbers, $M$ is the Earth's mass, $g$ is the mean surface gravity and $P_{n}$ are Legendre polynomials. To accelerate the computation, the loading effect is interpolated from tabulated values given by Pagiatakis (1988). The user can modify this table in order to consider different 
Earth models or to evaluate the contribution of individual components, i.e., the effect of the perturbed density field ( $k_{n}$ dependent) or the displacement effect $\left(h_{n}\right.$ dependent). The difference between the loading effects based on the load Love numbers as given by Pagiatakis (1988), Farrell (1972) and Guo et al. (2004) is only $0.3 \mathrm{~nm} \mathrm{~s}^{-2}$ (for Vienna, 2000-2007).

The gravitational effect per unit mas is computed for points with $\psi>1^{\circ}$ using the equation given by Farrell (1972)

$$
g^{N}(\psi)=\frac{g}{4 M \sin (\psi / 2)} .
$$

To include the effect of the topography, the gravitational effect of mass points with $\psi \leq 1^{\circ}$ is based on Newton's and cosines laws

$$
g^{N}=G \frac{\left(d^{2}+\left(R+h_{S}\right)^{2}-\left(R+h_{P}\right)^{2}\right)}{2 d^{3}\left(R+h_{S}\right)},
$$

where $G$ is the gravitational constant, $d$ is the direct distance to the point mass of one $\mathrm{kg}, R$ is the radius of the replacement sphere and $h_{S}, h_{P}$ are the heights of the gravimeter and the point mass respectively. The radius of the replacement sphere was set in such a manner that the sphere surface matches the surface of the WGS84 ellipsoid (NIMA, 2000).

On input, mGlobe loads gridded water storage data. Besides the model version and layer, e.g. soil moisture or snow, the user can select the exclusion or inclusion of certain areas, the digital elevation model, water mass conservation enforcement between continents and oceans (see below for details), and the minimum value of $\psi$ as the threshold between the local and the global zone (between 0.05 and $1.00^{\circ}$ ). To minimize the effect of a discontinuity at the boundary between the local and global zone, i.e., between the local and global hydrological model, this threshold 
should be set to a value for which water storage variations have minimum sensitivity on surface gravity at the measurement point. The dependency of the gravity effect on the integration radius for all three study sites is shown in Figure 2. In this example, the gravity effect in terms of both attraction and loading was computed using the GLDAS/NOAH monthly water storage anomaly (here February 2011) relative to the long term average of each grid cell. The differences between the sites reflect the position of the sensor with respect to the topography, the distance to the ocean, i.e., to an area with no soil moisture or snow variations, as well as different hydrological conditions in the area around Sutherland compared to the situation in Europe at the selected time epoch. Although the ideal threshold is sitedependent, the smallest sensitivity can be observed for these study sites at about $0.1^{\circ}$ to $1.0^{\circ}$. The continental water storage effects refer to $\psi \geq 0.1^{\circ}$ hereafter.

The mGlobe exclusion and inclusion options allow for a fast manipulation of hydrological model input. The contribution of certain areas, e.g. of a large river basin, to the gravity signal at the observation point can be assessed using the inclusion polygon. The exclusion option may be used to set the mass variations in Greenland or Antarctica to zero because the hydrological models often do not provide reliable data for these regions (e.g. Rodell et al., 2004). The mass enforcement option was designed to cope with a variable global sum of the total water storage in time. Part of this variability is due to the seasonal and interannual continent-ocean water exchange while the other part arises from model artefacts, such as impacts of the initialisation phase of model runs or deficient model structure. Such model deficiencies may introduce an artificial trend of continental water storage in the model output. To minimize this effect, similar to the GGP/Strasbourg Loading Service, mGlobe allows for distributing a com- 
pensating uniform water layer over the oceans and large lakes (defined by user). The layer thickness is determined by comparing the current epoch and the longterm average. For the example of Sutherland and the GLDAS/MOS model, the gravity response of this layer can be decomposed into a trend of $7.9 \pm 0.8 \mathrm{~nm} \mathrm{~s}^{-2}$ per year between 2000 and 2003 and a seasonal variation with an amplitude of $4.7 \pm 0.4 \mathrm{~nm} \mathrm{~s}^{-2}$ (Figure 3). After this period, the trend decreases significantly to $0.8 \pm 0.2 \mathrm{~nm} \mathrm{~s}^{-2}$. The seasonal amplitude is smaller for models like GLDAS/CLM or ERA Interim, i.e., $3.1 \pm 0.3 \mathrm{~nm} \mathrm{~s}^{-2}$. All models show higher amplitude compare to altimetry-based non-steric global mean sea level variations presented in Chen et al. (2005), where the converted annual gravity effect is equal to $1.6 \mathrm{~nm} \mathrm{~s}^{-2}$ and the linear trend to $1.3 \mathrm{~nm} \mathrm{~s}^{-2}$ per year.

The inclusion of a digital elevation model is recommended for mountain sites. The maximum difference between the monthly gravity effects computed using a spherical approximation and a digital elevation model exceeded $2.6 \mathrm{~nm} \mathrm{~s}^{-2}$ for Conrad, $0.6 \mathrm{~nm} \mathrm{~s}^{-2}$ for Sutherland and only $0.3 \mathrm{~nm} \mathrm{~s}^{-2}$ for Vienna. These results were obtained using the ETOPO1 (one minute resolution) digital elevation model (Amante and Eakins, 2009). These results were obtained using and GLDAS/NOAH model between 2000 and 2012. The influence of the temporal resolution was analysed using MERRA total water storage variations (Table 3). The temporal resolution of the input model has a larger influence on the gravity effect than its spatial resolution. Different spatial resolutions affect primarily the seasonal variation as compared to sub-diurnal variations. A maximum difference between the GLDAS/NOAH $0.25^{\circ}$ model and the $1.00^{\circ}$ model of $1.7 \mathrm{~nm} \mathrm{~s}^{-2}$ was found. These differences are relatively small in comparison to the discrepancies between different models. Figure 4 shows the continental water 
storage effect computed for Conrad observatory using selected models supported by mGlobe. The fitted annual amplitude of the difference between GLDAS/CLM and GLDAS/MOS is $8.3 \pm 0.2 \mathrm{~nm} \mathrm{~s}^{-2}$, i.e., $75 \%$ of the average annual amplitude (computed using all GLDAS, MERRA and ERA models). This is an extreme value considering the high precision of SGs and the amplitude of other signals of interest. To evaluate the mGlobe results, the continental water storage effect was compared to the results of the GGP/Strasbourg Loading service that provides hydrological effects for four models. For the GLDAS/NOAH model, the daily differences did not exceed $1.2 \mathrm{~nm} \mathrm{~s}^{-2}$ for either study site. This difference might be caused by various factors like the inclusion of a digital elevation model, exclusion of different areas or the use of a different Earth model.

\section{Non-tidal ocean loading}

The non-tidal ocean loading effect is computed in the same way as the continental water storage effect. An auxiliary grid with a spatial resolution of $0.1^{\circ}$ is used to identify grid cells over the oceans and continents. This grid can by modified if higher resolution of coastlines is required. As input, mGlobe loads gridded data sets of ocean bottom pressure variations. In accordance with the continental water storage effect, the mass conservation can be enforced by subtracting an area average over the global ocean (Greatbatch, 1994). An additional option allows for computing the gravity response to a coupled hydrological model covering continents and oceans. This option minimizes the uncertainty related to the mass exchange between oceans and continents although the development of such model is difficult. Alternatively, a monthly GRACE-based water storage data set covering the whole Earth can be incorporated from the ICGEM web ser- 
vice $^{5}$. However, it is recommended to use ocean bottom pressure models with higher temporal resolution, as discussed in Boy and Lyard (2008). The influence of the temporal resolution on the non-tidal ocean loading effect in Sutherland was assessed using the Ocean Model for Circulation and Tides (OMCT) model (Dobslaw and Thomas, 2007) for 2013. The ocean bottom pressure is the sum of the water column and atmospheric pressure. This is in compliance with the computed atmospheric effect where the loading effect over the ocean was set to zero. The maximum differences between the highest available resolution of 6 hours and linearly interpolated values from 12 and 24 hour sampling was $1.9 \mathrm{~nm} \mathrm{~s}^{-2}$ and $3.6 \mathrm{~nm} \mathrm{~s}^{-2}$, respectively. These are relatively high values since the maximum amplitude of the effect reached $10.1 \mathrm{~nm} \mathrm{~s}^{-2}$ only. The non-tidal ocean loading effect in Vienna and Conrad is $38 \%$ smaller than in Sutherland but still observable assuming the SG precision of $1 \mathrm{~nm} \mathrm{~s}^{-2}$ (Hinderer et al., 2007).

Figure 5 shows the comparison of the non-tidal ocean loading effect computed using the OMCT and ECCO models. The black line represents gravity residuals corrected for mean continental water storage, atmospheric effect as well as the local soil moisture and groundwater variations. The local corrections were computed using in-situ observations and detailed a digital elevation model that also represents the underground structure housing the SG at this site. The OMCT model shows good agreement with gravity residuals while the use of the ECCO model results in an underestimation of the non-tidal ocean loading effect. As in the case of the continental water storage effect, the discrepancies between models are significant. It is worth mentioning that the ECCO ocean bottom pressure

\footnotetext{
${ }^{5}$ http://icgem.gfz-potsdam.de/ICGEM/
} 
model, sampled every 12 hours, covers oceans only up to a latitude of $-72.5^{\circ}$. In addition, the diurnal tides related to atmosphere are preserved in OMCT and not in ECCO.

\section{Atmospheric effect}

The computation of the atmospheric effect is based on the freely available ERA Interim or MERRA model. These models offers a maximal time resolution of 6 hours and a spatial resolution of approximately $0.75^{\circ}$ (available in Gaussian grid) or $0.5^{\circ} \times 0.67^{\circ}$ respectively. The ERA model consists of 37 vertical layers and reaches up to an altitude equivalent to $1 \mathrm{hPa}$, i.e., approximately $47 \mathrm{~km}$. The MERRA model reaches up to $0.1 \mathrm{hPa}$ (approx. $62 \mathrm{~km}$ ) and consists of 42 pressure levels. The altitude of pressure levels varies in time and space. The lower boundary is defined by the orography, i.e., the reference surface of the atmospheric model. As in the case of the continental water storage, the computation of the atmospheric effect is divided into several zones with different degree of spatial discretization. The loading effect in all zones is computed using tabulated values of the gravity effect per $1 \mathrm{hPa}$ load as given by Merriam (1992). As mentioned in the previous section, no loading effect is computed for points over the oceans. The gravitational effect for areas with $\psi<20^{\circ}$ is computed using a tesseroid approximation as described in Heck and Seitz (2007). Since this is only an approximate solution of the spherical tesseroid, an interpolation to a finer grid is required for the area close to the computation point. No interpolation in vertical direction is performed throughout the computation. A point mass approximation as given by Farrell (1972) is used for areas with $\psi \geq 20^{\circ}$. The model pressure $(p)$, temperature $(T)$ and specific humidity $(q)$ are converted to density $(\rho)$ using equation derived 
297

from Etling (2002)

$$
\rho=\frac{p}{287 T(1-q+q / 0.62197)} .
$$

The tesseroid density is the mean between the upper and lower pressure level. The two metre dew point temperature downloaded for the lower boundary, i.e., the orography, is transformed to the specific humidity using the following equations

$$
q=\frac{0.62197 e_{s a t}(T)}{p-(1-0.62197) e_{s a t}(T)},
$$

$$
e_{\text {sat }}(T)=611.21 \exp \left\{a_{3}\left(\frac{T-273.16}{T-a_{4}}\right)\right\},
$$

where $e_{\text {sat }}(T)$ is the saturation water vapour pressure, $a_{3}=17.502$ and $a_{4}=$ 32.19 $\mathrm{K}$ if $T \geq 273.16 \mathrm{~K}$, otherwise $a_{3}=22.587$ and $a_{4}=-20.7 \mathrm{~K}$ (ECMWF, 2010).

\subsection{Atmospheric correction factor}

As mentioned in Section 2, the computation includes also the local zone, i.e., the atmospheric effect is integrated over the whole Earth. Nevertheless, a consideration of a residual effect related to the deficient spatial and temporal resolution of used atmospheric models is required. Ideally, such effect would be computed using high-resolution atmospheric models or observations collected in the local zone. In most cases, only air pressure variations observed with an in-situ sensor close to the gravimeter are available. Similarly to the single admittance approach, the proposed computation procedure exploits the relation between the gravity effect and pressure residuals. However, the procedure does not utilize observed gravity variations. Instead, the gravitational effect of the atmosphere is computed by considering the differences between the orography and real topography. 
The pressure residuals are the differences between the in-situ and the interpolated model pressure.

Assuming a constant discretization of the atmosphere, i.e., neglecting the altitude variation of the upper boundary, the pressure residuals are directly related to the gravity effect as the air density is computed using the air pressure, temperature and specific humidity (equation (4)). Temperature and humidity introduce seasonal and diurnal variations into the density. At most sites, the seasonal variation exceeds the diurnal fluctuations. As shown in Klügel and Wziontek (2009), the seasonal variations of the upper part of the atmosphere are opposite to the lower part, and the total atmospheric effect is strongly anti-correlated to air pressure but not to air temperature. Nevertheless, the deficient spatial resolution of the atmospheric model results in a volume excess or deficit between the model orography and the actual topography. The corresponding gravity effect is therefore correlated to the air temperature of the lower part of the atmosphere. Assuming an isothermal atmosphere, the decrease of the air pressure with altitude depends on the temperature as well, and can be calculated as follows (Etling, 2002)

$$
p(z)=p_{0} \exp \left(-\frac{g z}{287 T(1+0.608 q)}\right)
$$

where $z$ is the altitude difference, $p_{0}$ is the air pressure at the lower boundary and $p(z)$ at the upper boundary. This formula can be used to effectively describe the air pressure differences between orography and topography, i.e., the pressure residuals. The following results were obtained for the ERA Interim model. As mentioned in the introduction, the Atmacs service provides atmospheric effects for selected SGs using weather models with spatial resolution of $7 \mathrm{~km}$ for European sites (20 km worldwide). Thus, differences between mGlobe and Atmacs, 
i.e., the residual gravity effect, should reflect predominantly the deficient resolution of ERA Interim. Figure 6 shows these differences superimposed by in-situ temperature observations at the Conrad observatory. This figure confirms the expected relationship between the residual gravity effect and the pressure residuals. The correlation of these time series at the seasonal time scale could also be caused by the lower altitude of the uppermost layer of the ERA Interim model compared to models utilized in Atmacs. The minimal computation altitude was discussed in Klügel and Wziontek (2009), concluding that the atmospheric model should reach up to $50 \mathrm{~km}$. We found that the gravitational effect of the last layer, i.e., from 2 to $1 \mathrm{hPa}$, shows minimal variability (below $0.1 \mathrm{~m} \mathrm{~s}^{-2}$ ). It is therefore unlikely that the gravity effect differences shown in figure 6 could be caused by the missing layer between 1 and $0 \mathrm{hPa}$.

The parameter hereafter denoted as correction factor converts the pressure residuals to residual gravity effect and its value is site- and model-dependent. To estimate the correction factor, we computed the gravitational effect of the air between the topography given by a digital elevation model and the ERA Interim orography up to $\psi=0.1^{\circ}$. This radius reflects the small differences between mGlobe and Atmacs beyond the local zone. The air density was computed using ERA Interim outputs, equations (4) to (7) and a temperature gradient of $-0.65 \mathrm{~K} / 100 \mathrm{~m}$ (US-CESA, 1976). Figure 7 shows the differences between topography and orography as well as the computed gravitational effect as a function of pressure residuals at the Conrad observatory. The slope of the plotted line determines the correction factor, i.e., $-3.63 \pm 0.02 \mathrm{~nm} \mathrm{~s}^{-2} / \mathrm{hPa}$ for Conrad, $-3.00 \pm 0.05 \mathrm{~nm} \mathrm{~s}^{-2} / \mathrm{hPa}$ for Vienna and $-3.66 \pm 0.03 \mathrm{~nm} \mathrm{~s}^{-2} / \mathrm{hPa}$ for Sutherland. It should be noted that this approach will not always be applicable. In a 
specific situation, the ERA orography height and air pressure might match the insitu values but the smooth orography will unlikely fit the undulated topography of the study area. Thus, the pressure residuals will not show any seasonal variation whereas the gravitational effect will. In this and similar cases, the correction factor cannot fully minimize the residual effect but still is often the only option due to the lack of local high-resolution atmospheric models. A similar conclusion holds true for the correction of a deficient temporal resolution. The aim of this correction is to restore the total atmospheric effect, not only the local contribution. The low sampling frequency (6 hours for ERA Interim) prevents the reconstruction of the full signal regardless of the differences between orography and topography. Here again, the pressure residuals can be used to restore the major part of the variation. The value of the correction factors for this case may however differ from those determined using the differences between orography and topography. Nevertheless, it is unlikely that the correction factor for deficient temporal resolution, i.e., for frequencies higher than 2 cycles per day, will exceed the range -4.5 to $-2.5 \mathrm{~nm} \mathrm{~s}^{-2} / \mathrm{hPa}$ (e.g. Hinderer et al., 2014). The amplitudes of pressure residuals high-pass filtered to 2 cycles per day, i.e., half the model temporal resolution, are about $2 \mathrm{hPa}$ for Conrad, $1.7 \mathrm{hPa}$ for Sutherland and $1.9 \mathrm{hPa}$ for Vienna. The corresponding gravity effect differences (spatial minus temporal) are thus negligible.

The final comparison of gravity residuals corrected for atmospheric effect using mGlobe, Atmacs and the single admittance approach is shown in Figure 8. The Atmacs service provides the atmospheric correction based on various weather models and computation procedures. We used the following versions: The LM2 (radius of the local model $12 \mathrm{~km}$, radius of the regional model $18^{\circ}$ ) plus GME256/GME384 
for Conrad, LM2 (12 km, 18 $)$ plus GME192 for Vienna and GME256/GME384 $(300 \mathrm{~km})$ for Sutherland. The unknown orography of weather models used in Atmacs prevented the computation of the model-specific correction factors. Therefore we used factor equal to $-3 \mathrm{~nm} \mathrm{~s}^{-2} / \mathrm{hPa}$. Compared to the single admittance approach, the gravity residuals corrected for atmospheric effects computed by mGlobe and Atmacs show significantly reduced variation, especially at the Conrad observatory and in Vienna. Neither correction is able to reduce the strong barometric tides observed in Sutherland. The histograms on the right of Figure 8 highlight the small differences between Atmacs and mGlobe. The standard deviation of these differences ranges from $1.1 \mathrm{~nm} \mathrm{~s}^{-2}$ for Sutherland to $1.8 \mathrm{~nm} \mathrm{~s}^{-2}$ for Vienna. It should be noted that these values depend on the correction factors applied here and may change after using model-specific factors for Atmacs.

\section{Conclusions}

We have developed a Matlab ${ }^{\circledR} /$ Octave-based tool for the computation of large scale hydrological and atmospheric contributions to gravity variations observed by terrestrial gravimeters. This program offers a unique possibility to compute the continental water storage, non-tidal ocean loading and atmospheric effects for an arbitrary location worldwide. Another benefit is the support of 7 freely available global hydrological models, 3 ocean bottom pressure models, two atmospheric models and GRACE mass grid models as input for the computations. Other hydrological or ocean models can be transformed to the mGlobe supported file format using the build-in conversion tool. As shown in this study, the discrepancies between individual models affect the continental water storage effect as well as the non-tidal ocean loading effect significantly. Differences of more 
than $75 \%$ were found. In addition to model comparisons, we tested the influence of the models' temporal and spatial resolution. The temporal resolution plays a key role especially for the non-tidal ocean loading and atmospheric effects. The atmospheric effect is additionally strongly affected by deficient spatial resolution. Nevertheless, the corresponding gravity effect can be effectively reduced by means of site-specific correction factors. The proposed correction factor takes into consideration real topography and the differences between in-situ and model air pressure. Its value is determined independently of observed gravity variations. The continental water storage effect shows relatively low sensitivity to both temporal and spatial resolution. This result was computed for points beyond the spherical distance of $0.1^{\circ}$. This value was chosen to minimize the possible discontinuities at the border between the local and global hydrological models. However, the minimum computation radius can be set by the user. Supplementary features like the exclusion of certain areas of hydrological models, enforcement of the mass conservation principle, use of high-resolution coastlines or the inclusion of digital elevation models allow users to obtain more specific results compared to alternative services of large scale gravity effects.

\section{Acknowledgements}

The authors thank Henryk Dobslaw (GFZ German Research Centre for Geosciences) for the provision of OMCT ocean bottom pressure model and Hartmut Wziontek (Federal Agency for Cartography and Geodesy (BKG)) for fruitful discussion on atmospheric effects. The authors would also like to thank Branislav Hábel (Slovak University of Technology) for providing us with tidal analyses as well as the ZAMG (Austria), the owner of Conrad observatory. The data used in 
this study were acquired as part of the mission of NASA's Earth Science Division and archived and distributed by the Goddard Earth Sciences (GES) Data and Information Services Center (DISC). GRACE land data processing algorithms were provided by Sean Swenson, and supported by the NASA MEaSUREs Program. ECMWF ERA-Interim data used in this study have been obtained from the ECMWF data server.

\section{References}

Amante, C., Eakins, B., 2009. ETOPO1 1 Arc-Minute Global Relief Model: Procedures, Data Sources and Analysis. Technical Memorandum NESDIS NGDC24. Technical Report. NOAA National Geophysical Data Center.

Boy, J.P., Hinderer, J., 2006. Study of the seasonal gravity signal in superconducting gravimeter data. Journal of Geodynamics 41, 227-233.

Boy, J.P., Longuevergne, L., Boudin, F., Jacob, T., Lyard, F., Llubes, M., Florsch, N., Esnoult, M.F., 2009. Modelling atmospheric and induced non-tidal oceanic loading contributions to surface gravity and tilt measurements. Journal of Geodynamics $48,182-188$.

Boy, J.P., Lyard, F., 2008. High-frequency non-tidal ocean loading effects on surface gravity measurements. Geophysical Journal International 175, 35-45.

Chambers, D.P., Bonin, J.A., 2012. Evaluation of release-05 GRACE timevariable gravity coefficients over the ocean. Ocean Sci. 8, 859-868. OS.

Chambers, D.P., Willis, J.K., 2010. A global evaluation of ocean bottom pressure 
from GRACE, OMCT, and steric-corrected altimetry. Journal of Atmospheric and Oceanic Technology 27, 1395-1402.

Chen, J.L., Wilson, C.R., Tapley, B.D., Famiglietti, J.S., Rodell, M., 2005. Seasonal global mean sea level change from satellite altimeter, GRACE, and geophysical models. Journal of Geodesy 79, 532-539.

Creutzfeldt, B., Ferré, T., Troch, P., Merz, B., Wziontek, H., Güntner, A., 2012. Total water storage dynamics in response to climate variability and extremes: Inference from long-term terrestrial gravity measurement. Journal of Geophysical Research: Atmospheres 117, D08112.

Creutzfeldt, B., Güntner, A., Klügel, T., Wziontek, H., 2008. Simulating the influence of water storage changes on the superconducting gravimeter of the Geodetic Observatory Wettzell, Germany. Geophysics 73, WA95-WA104.

Creutzfeldt, B., Güntner, A., Wziontek, H., Merz, B., 2010. Reducing local hydrology from high-precision gravity measurements: a lysimeter-based approach. Geophysical Journal International 183, 178-187.

van Dam, T.M., 2001. Gravity changes due to continental water storage. Journal of the Geodetic Society of Japan 47, 6.

van Dam, T.M., Wahr, J., 1998. Modeling environment loading effects: a review. Physics and Chemistry of the Earth 23, 1077-1087.

Dee, D.P., Uppala, S.M., Simmons, A.J., Berrisford, P., Poli, P., Kobayashi, S., Andrae, U., Balmaseda, M.A., Balsamo, G., Bauer, P., Bechtold, P., Beljaars, A.C.M., van de Berg, L., Bidlot, J., Bormann, N., Delsol, C., Dragani, R., 
Fuentes, M., Geer, A.J., Haimberger, L., Healy, S.B., Hersbach, H., Hólm, E.V., Isaksen, L., Kàllberg, P., Köhler, M., Matricardi, M., McNally, A.P., MongeSanz, B.M., Morcrette, J.J., Park, B.K., Peubey, C., de Rosnay, P., Tavolato, C., Thépaut, J.N., Vitart, F., 2011. The ERA-Interim reanalysis: configuration and performance of the data assimilation system. Quarterly Journal of the Royal Meteorological Society 137, 553-597.

Dobslaw, H., Thomas, M., 2007. Simulation and observation of global ocean mass anomalies. Journal of Geophysical Research: Oceans 112, C05040.

Döll, P., Kaspar, F., Lehner, B., 2003. A global hydrological model for deriving water availability indicators: model tuning and validation. Journal of Hydrology $270,105-134$.

ECMWF, 2010. IFS documentation CY36r1: IV. Physical processes. Report. European Centre for Medium-Range Weather Forecasts. Reading, England, 171 pp.

Egbert, G.D., Erofeeva, S.Y., 2002. Efficient inverse modeling of barotropic ocean tides. Journal of Atmospheric and Oceanic Technology 19, 183-204.

Etling, D., 2002. Theoretische Meteorologie: Eine Einfhrung. Springer Verlag, Heidelberg, Germany. 2nd edition, [in German] 354 pp.

Farrell, W.E., 1972. Deformation of the Earth by surface loads. Reviews of Geophysics 10, 761-797.

Fukumori, I., 2002. A partitioned kalman filter and smoother. Monthly Weather Review 130, 1370-1383. 
Greatbatch, R.J., 1994. A note on the representation of steric sea level in models that conserve volume rather than mass. Journal of Geophysical Research: Oceans 99, 12767-12771.

Guo, J.Y., Li, Y.B., Huang, Y., Deng, H.T., Xu, S.Q., Ning, J.S., 2004. Green's function of the deformation of the Earth as a result of atmospheric loading. Geophysical Journal International 159, 53-68.

Hasan, S., Troch, P.A., Boll, J., Kroner, C., 2006. Modeling the hydrological effect on local gravity at Moxa, Germany. Journal of Hydrometeorology 7, 346-354.

Heck, B., Seitz, K., 2007. A comparison of the tesseroid, prism and point-mass approaches for mass reductions in gravity field modelling. Journal of Geodesy $81,121-136$.

Hinderer, J., Crossley, D., Warburton, R.J., 2007. 3.04 - Gravimetric Methods Superconducting Gravity Meters, in: Schubert, G. (Ed.), Treatise on Geophysics. Elsevier, Amsterdam, Netherlands, pp. 65-122.

Hinderer, J., Hector, B., Boy, J.P., Riccardi, U., Rosat, S., Calvo, M., Littel, F., 2014. A search for atmospheric effects on gravity at different time and space scales. Journal of Geodynamics 80, 50-57.

Hinderer, J., Pfeffer, J., Boucher, M., Nahmani, S., Linage, C., Boy, J.P., Genthon, P., Seguis, L., Favreau, G., Bock, O., Descloitres, M., 2012. Land water storage changes from ground and space geodesy: First results from the GHYRAF (Gravity and Hydrology in Africa) experiment. Pure and Applied Geophysics $169,1391-1410$. 
Kalnay, E., Kanamitsu, M., Kistler, R., Collins, W., Deaven, D., Gandin, L., Iredell, M., Saha, S., White, G., Woollen, J., Zhu, Y., Leetmaa, A., Reynolds, R., Chelliah, M., Ebisuzaki, W., Higgins, W., Janowiak, J., Mo, K.C., Ropelewski, C., Wang, J., Jenne, R., Joseph, D., 1996. The NCEP/NCAR 40year Reanalysis project. Bulletin of the American Meteorological Society 77, 437-471.

Kim, S.B., Lee, T., Fukumori, I., 2007. Mechanisms controlling the interannual variation of mixed layer temperature averaged over the Niño-3 region. Journal of Climate 20, 3822-3843.

Klügel, T., Wziontek, H., 2009. Correcting gravimeters and tiltmeters for atmospheric mass attraction using operational weather models. Journal of Geodynamics 48, 204-210.

Kroner, C., Thomas, M., Dobslaw, H., Abe, M., Weise, A., 2009. Seasonal effects of non-tidal oceanic mass shifts in observations with superconducting gravimeters. Journal of Geodynamics 48, 354-359.

Landerer, F.W., Swenson, S.C., 2012. Accuracy of scaled GRACE terrestrial water storage estimates. Water Resources Research 48, W04531.

Longuevergne, L., Boy, J.P., Florsch, N., Viville, D., Ferhat, G., Ulrich, P., Luck, B., Hinderer, J., 2009. Local and global hydrological contributions to gravity variations observed in Strasbourg. Journal of Geodynamics 48, 189-194.

Lyard, F., Lefevre, F., Letellier, T., Francis, O., 2006. Modelling the global ocean tides: modern insights from FES2004. Ocean Dynamics 56, 394-415. 
Matsumoto, K., Takanezawa, T., Ooe, M., 2000. Ocean tide models developed by assimilating TOPEX/POSEIDON altimeter data into hydrodynamical model: A global model and a regional model around Japan. Journal of Oceanography $56,567-581$.

Merriam, J.B., 1992. Atmospheric pressure and gravity. Geophysical Journal International 109, 488-500.

Naujoks, M., Kroner, C., Weise, A., Jahr, T., Krause, P., Eisner, S., 2010. Evaluating local hydrological modelling by temporal gravity observations and a gravimetric three-dimensional model. Geophysical Journal International 182, 233249.

Neumeyer, J., Barthelmes, F., Kroner, C., Petrovic, S., Schmidt, R., Virtanen, H., Wilmes, H., 2008. Analysis of gravity field variations derived from superconducting gravimeter recordings, the GRACE satellite and hydrological models at selected European sites. Earth, Planets and Space 60, 505-518.

NIMA, 2000. World Geodetic System 1984: Its definition and relationships with local geodetic systems. Report TR8350.2. National Imagery and Mapping Agency. St. Louis, USA, 175 pp.

Pagiatakis, S.D., 1988. Ocean tide loading on a self-gravitating, compressible, layered, anisotropic, viscoelastic and rotating Earth with solid inner core and fluid outer core. Report. University of New Brunswick. Fredericton, Canada, $163 \mathrm{pp}$.

Reichle, R.H., Koster, R.D., De Lannoy, G.J.M., Forman, B.A., Liu, Q., Ma- 
hanama, S.P.P., Touré, A., 2011. Assessment and enhancement of MERRA Land surface hydrology estimates. Journal of Climate 24, 6322-6338.

Rodell, M., Houser, P.R., Jambor, U., Gottschalck, J., Mitchell, K., Meng, C.J., Arsenault, K., Cosgrove, B., Radakovich, J., Bosilovich, M., Entin, J.K., Walker, J.P., Lohmann, D., Toll, D., 2004. The global land data assimilation system. Bulletin of the American Meteorological Society 85, 381-394.

Swenson, S., Wahr, J., 2006. Post-processing removal of correlated errors in GRACE data. Geophysical Research Letters 33, 1-4.

US-CESA, 1976. U. S. Committee on Extension to the Standard Atmosphere: The U.S. Standard Atmosphere 1976. Technical Report. U.S. Government Printing Office.

Van Camp, M., Vauterin, P., 2005. Tsoft: graphical and interactive software for the analysis of time series and Earth tides. Computers \& Geosciences 31, 631-640.

Van Camp, M., de Viron, O., Métivier, L., Meurers, B., Francis, O., 2014. The quest for a consistent signal in ground and GRACE gravity time-series. Geophysical Journal International 197, 192-201.

Virtanen, H., Tervo, M., Bilker-Koivula, M., 2006. Comparison of superconducting gravimeter observations with hydrological models of various spatial extents. Bulletin d'Informations Marées Terrestres 142, 8.

Warburton, R.J., Goodkind, J.M., 1977. The influence of barometric-pressure variations on gravity. Geophysical Journal of the Royal Astronomical Society 48, 281-292. 
Weise, A., Kroner, C., Abe, M., Creutzfeldt, B., Förste, C., Güntner, A., Ihde, J., Jahr, T., Jentzsch, G., Wilmes, H., Wziontek, H., Petrovic, S., 2012. Tackling mass redistribution phenomena by time-dependent GRACE- and terrestrial gravity observations. Journal of Geodynamics 59-60, 82-91.

Wenzel, H.G., 1996. The nanogal software: Earth tide data processing package ETERNA 3.30. Bulletin d'Informations Marées Terrestres 124, 9425-9439.

Wziontek, H., Wilmes, H., Wolf, P., Werth, S., Güntner, A., 2009. Time series of superconducting gravimeters and water storage variations from the global hydrology model WGHM. Journal of Geodynamics 48, 166-171. 
Table 1: Global hydrological and ocean models supported in mGlobe. Other models can be converted to the default file format using a build-in conversion console.

\begin{tabular}{|c|c|c|}
\hline Model & Source/Download & Reference \\
\hline GLDAS/CLM & direct download (OPeNDAP server) & (Rodell et al., 2004) \\
\hline GLDAS/MOS & direct download (OPeNDAP server) & (Rodell et al., 2004) \\
\hline GLDAS/VIC & direct download (OPeNDAP server) & (Rodell et al., 2004) \\
\hline GLDAS/NOAH & direct download (OPeNDAP server) & (Rodell et al., 2004) \\
\hline MERRA/Land & direct download (OPeNDAP server) & (Reichle et al., 2011) \\
\hline ERA Interim & apps.ecmwf.int/datasets/ & (Dee et al., 2011) \\
\hline NCEP Reanalysis-2 & www.esrl.noaa.gov/psd/data & (Kalnay et al., 1996) \\
\hline \multirow[t]{2}{*}{ GRACE/Land } & grace.jpl.nasa.gov/data/ & (Landerer and Swenson, 2012) \\
\hline & & (Swenson and Wahr, 2006) \\
\hline \multirow[t]{2}{*}{ ECCO-JPL } & grace.jpl.nasa.gov/data/ & (Fukumori, 2002) \\
\hline & ftp://snowwhite.jpl.nasa.gov/ & (Kim et al., 2007) \\
\hline $\mathrm{ECCO} 2$ & ftp://ecco2.jpl.nasa.gov/ & \\
\hline OMCT & isdc.gfz-potsdam.de & (Dobslaw and Thomas, 2007) \\
\hline \multirow[t]{2}{*}{ GRACE/Ocean } & grace.jpl.nasa.gov/data/ & (Chambers and Willis, 2010) \\
\hline & & (Chambers and Bonin, 2012) \\
\hline
\end{tabular}


Table 2: Study sites with superconducting gravimeters used for the evaluation of mGlobe results. The $\phi$ symbol represents the latitude and $\lambda$ the longitude (both rounded to four decimal places).

\begin{tabular}{l|ccccc}
\hline Site & SG & $\begin{array}{c}\phi \\
\left({ }^{\circ}\right)\end{array}$ & $\begin{array}{c}\lambda \\
\left({ }^{\circ}\right)\end{array}$ & $\begin{array}{c}\text { altitude } \\
(\mathrm{m})\end{array}$ & $\begin{array}{c}\text { distance to sea } \\
(\mathrm{km})\end{array}$ \\
\hline Conrad & $\mathrm{C} 025$ & 47.9283 & 15.8598 & 1044.12 & 300 \\
Sutherland & D037L & -32.3816 & 20.8111 & 1759.05 & 220 \\
Vienna & $\mathrm{C} 025$ & 48.2489 & 16.3565 & 192.74 & 350 \\
\hline
\end{tabular}


Table 3: The influence of temporal resolution on the continental water storage effect computed for time period between 2000-2012 and for $\psi \geq 0.1^{\circ}$. The columns show maximum differences and standard deviations obtained by comparing the original hourly MERRA Land (assimilation) model outputs to re-sampled values. All results are in $\mathrm{nm} \mathrm{s}^{-2}$.

\begin{tabular}{l|cccccccccc}
\hline Site & \multicolumn{3}{|c}{3 hours } & \multicolumn{2}{c}{6 hours } & \multicolumn{2}{c}{12 hours } & \multicolumn{2}{c}{24 hours } & \multicolumn{2}{c}{ month } \\
& $\max$ & std & $\max$ & std & $\max$ & std & $\max$ & std & $\max$ & std \\
\hline Conrad & 0.07 & 0.005 & 0.15 & 0.01 & 0.32 & 0.05 & 0.63 & 0.06 & 3.55 & 0.84 \\
Sutherland & 0.07 & 0.004 & 0.19 & 0.01 & 0.40 & 0.02 & 0.89 & 0.03 & 1.85 & 0.37 \\
Vienna & 0.04 & 0.004 & 0.09 & 0.01 & 0.24 & 0.04 & 0.48 & 0.05 & 3.05 & 0.71 \\
\hline
\end{tabular}




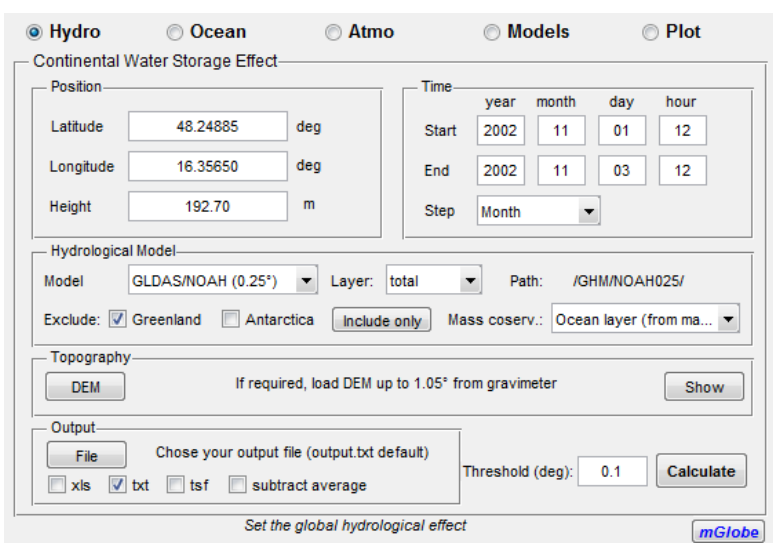

Figure 1: mGlobe graphical user interface of the continental water storage console. 


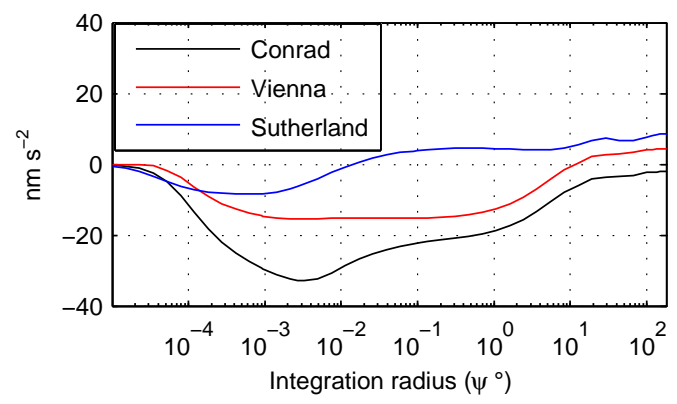

Figure 2: The hydrological gravity effect as a function of the spatial integration radius. The effect was computed using GLDAS/NOAH model output (soil moisture and snow storage) considering the difference between February 2011 and the mean for the period 2000 to 2010. 


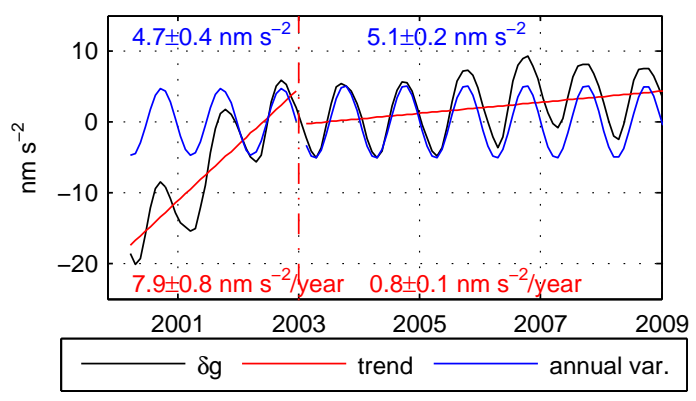

Figure 3: Gravity response $(\delta \mathrm{g})$ at Sutherland of the water mass variation of the GLDAS/MOS model by distributing a uniform water layer of variable thickness over the oceans before (black line) and after (blue line) trend correction (trends in red). 


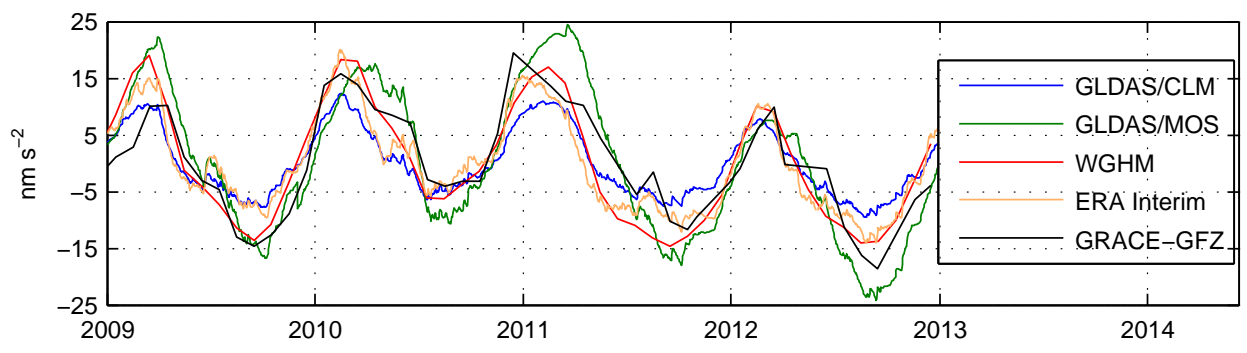

Figure 4: Continental water storage effect at the Conrad observatory computed for total water storage (TWS) simulated by different hydrological models, and for gridded GRACE-GFZ RL05 land TWS data. 


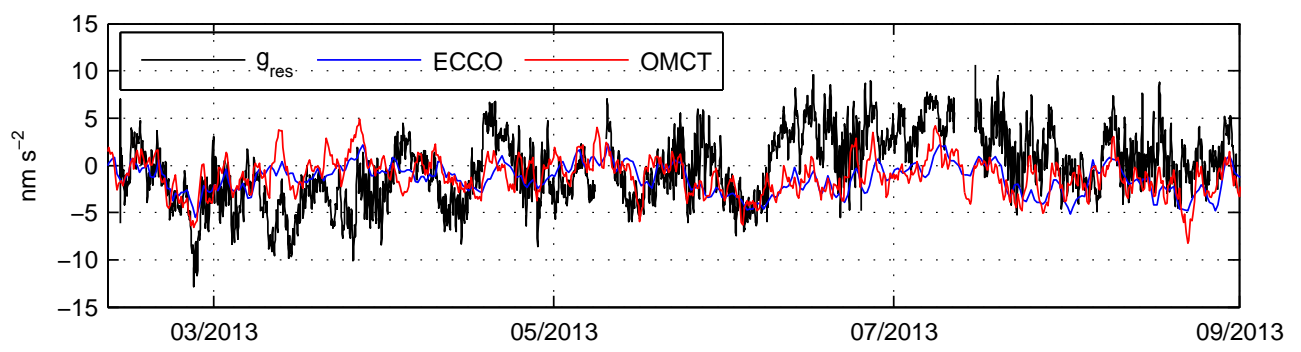

Figure 5: Non-tidal ocean loading effect in Sutherland computed using OMCT and ECCO models. The gravity residuals $\left(\mathrm{g}_{\text {res }}\right.$ ) were corrected for atmospheric, mean continental water storage and local hydrological effects. 


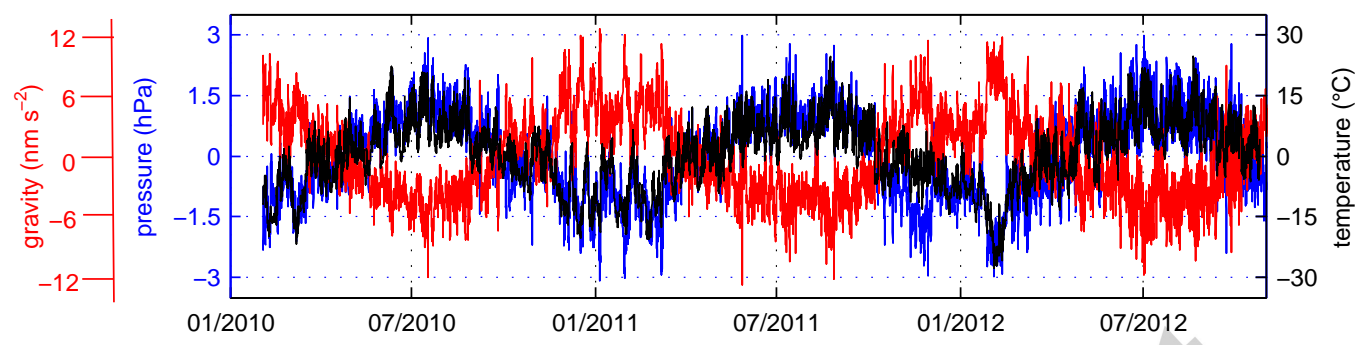

Figure 6: Pressure residuals (blue) and residual gravity effect (red) superimposed by in-situ temperature variation (black) observed at the Conrad observatory. The pressure and gravity residuals were computed as difference between Atmacs and mGlobe. 

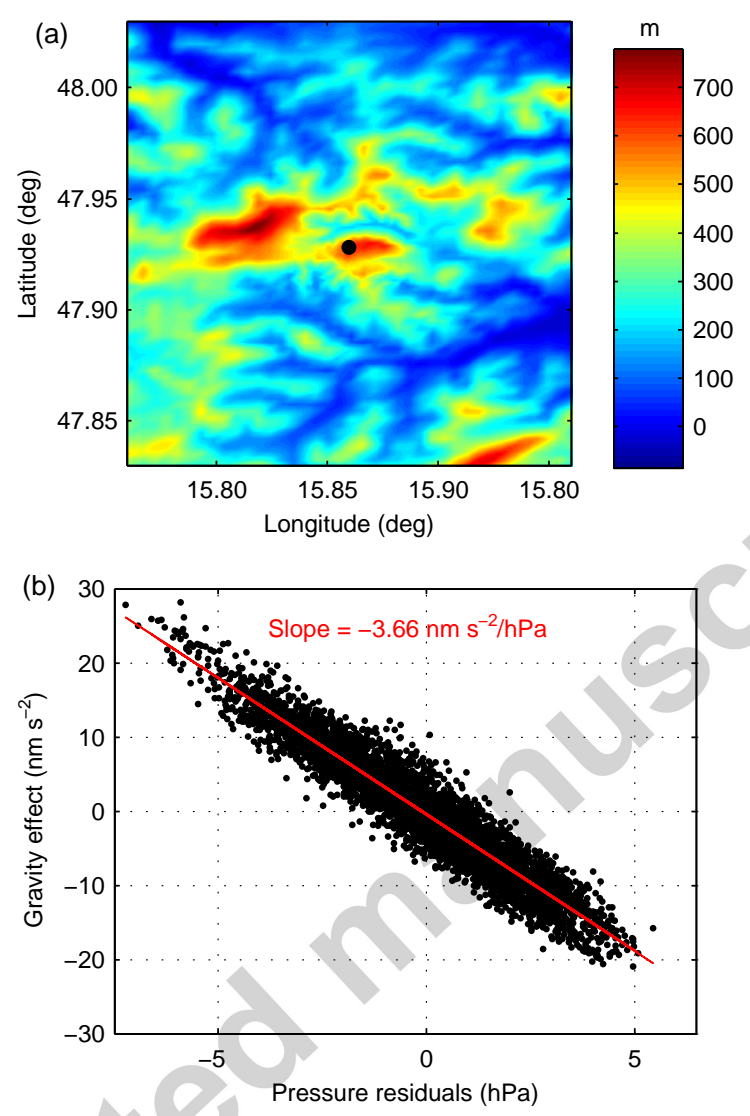

Figure 7: The difference between digital elevation model and ERA Interim orography at the Conrad observatory (a) and the gravitational effect as a function of pressure residuals (in-situ - ERA Interim) (b). 

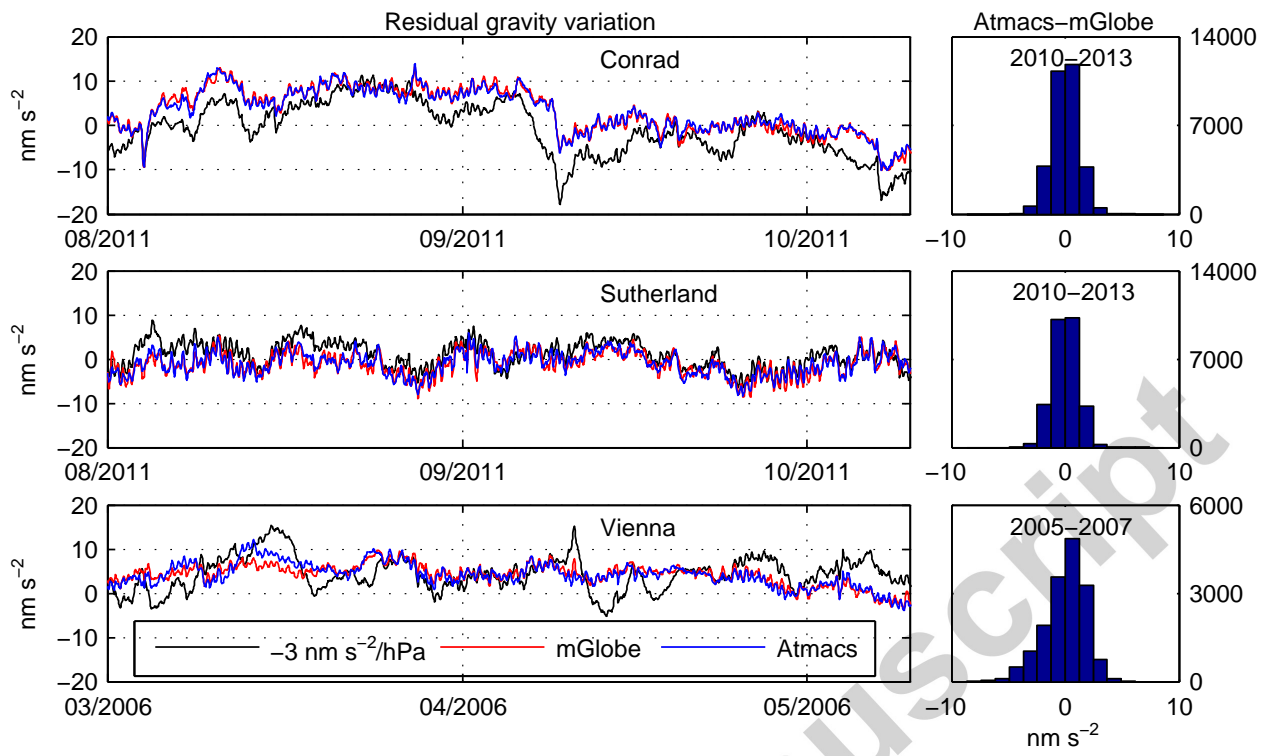

Figure 8: Gravity residuals corrected for atmospheric effect using different reductions, i.e., the single admittance factor $\left(-3 \mathrm{~nm} \mathrm{~s}^{-2} / \mathrm{hPa}\right)$, Atmacs and mGlobe outputs. The histograms on the right show the differences between Atmacs and mGlobe (both include the residual gravity effect). 